\title{
Egypt's nationally determined contributions to Paris agreement: review and recommendations
}

\author{
Lamiaa Abdallah* \\ Alexandria higher Institute of Engineering \& Technology (AIET) \\ * Corresponding author: lamiaa_abdallah@yahoo.com
}

\begin{abstract}
During Paris Agreement, a historic climate landmark signed in Paris in 2015, leaders of about 200 countries committed to limiting global warming well below $2^{\circ} \mathrm{C}$ above pre-industrial levels, and pursuing efforts to limit it to $1.5^{\circ} \mathrm{C}$ by 2100 . Each Country defined its commitments as Nationally Determined Contributions (NDCs). Egypt, with only $0.6 \%$ contribution to global emissions, is badly susceptible to climate change. Egypt submitted its NDCs in 2017 to be activated in 2020. Egypt's NDCs are too general and does not provide quantified targets nor plans for emission reductions. Moreover, Egypt's NDCs are conditional on receiving international funding of 73 Billion Dollars. This paper reviews Egypt's NDC to assess its true level of importance and to display Egypt's long-standing commitment to climate change efforts. Actions include reshaping the energy mix for electricity generation from ( $92 \%$ oil \& gas and $8 \%$ hydroelectric \& renewables) to (60\% natural gas with combined cycle, $35 \%$ renewables \& hydro and 5\% nuclear energy). In transport sector, fuel switching from oil to gas and promotion of electric vehicles can lead to at least $10 \%$ emission reduction in transport sector. Energy efficiency in industry, achieved by promoting high efficient motors, variable speed drives, waste heat recovery and replacing fluorinated refrigerants, can lead to a similar reduction in industry sector. Replacing inefficient lighting with LEDs, together with the use of energy efficient appliances, air conditioners and installing solar panels can lead to similar reduction in the building sector. These actions can be done with local resources besides firmly applying environmental regulations. It shows that a target of reducing CO2 emissions by $20 \%$ from current emissions of $250 \mathrm{MtCO} 2$ emissions by 2030 is possible. International funding is required for adaptation to the results of climate changes. The required technical and financial support for such adaptation needs extensive studies.
\end{abstract}

Keywords: Nationally Determined Contributions (NDCs); Climate Change; Global Warming; 2 Degrees Scenario (2DS); Paris Agreement; Egypt's NDC

\section{1- Introduction}

\section{A. Global Warming}

Planet Earth is naturally surrounded by a layer of Green House Gases (GHGs). GHGs include carbon dioxide $\left(\mathrm{CO}_{2}\right)$, methane $\left(\mathrm{CH}_{4}\right)$, nitrous oxide $\left(\mathrm{N}_{2} \mathrm{O}\right)$ and fluorinated gases. GHG layer allows the solar radiations to penetrate it, but when the Earth's surface reflect these radiations, it absorbs such radiations, keeping the Earth's atmosphere warm. Without GHGs, the average temperature of the Earth's surface would be $\left(-18^{\circ} \mathrm{C}\right)$ rather than the present average of $\left(15^{\circ} \mathrm{C}\right)[1]$.

Humans are adding extra GHGs to the atmosphere that disturb the natural GHGs balance. $\mathrm{CO}_{2}$ is released by burning fossil fuel to supply power, in industry and in transportation. $\mathrm{CH}_{4}$ 
is released by cattle farming, waste dumps and the production of oil and gas. $\mathrm{N}_{2} \mathrm{O}$ is released by chemical fertilizers and by burning fossil fuels. $\mathrm{CO}_{2}$ contributes for almost $75 \%$ of all GHG emissions. Other GHGs are compared to $\mathrm{CO}_{2}$ with respect to their equivalent Global Warming Potential (GWP). $\mathrm{CH}_{4}$ is 28 times more potent than $\mathrm{CO}_{2}$ as a GHG. If $1 \mathrm{~kg}$ of $\mathrm{N}_{2} \mathrm{O}$ is released, it will cause global warming equivalent to $265 \mathrm{~kg}$ of $\mathrm{CO}_{2}$ [2].

The emissions of $\mathrm{CO}_{2}$ in the atmosphere due to fuel combustion increases from nearly zero in the "pre-industrial" interval (about 1860) to a peak value of $33 \mathrm{Gt}$ in 2018 . The concentration of $\mathrm{CO}_{2}$ in the atmosphere increases from $280 \mathrm{ppm}$ in the pre-industrial intervals to about 415 ppm in May 2019 and the trend continues to increase as shown in Fig. 1 [3].

As the $\mathrm{CO}_{2}$ concentration increases, the GHGs layer becomes thicker, and more infrared radiations are absorbed, resulting in a rise in the temperature of the earth "Global Warming". The rise in the temperature of the earth or the "Global Warming" is recorded to be approximately $1^{\circ} \mathrm{C}$ since the pre-industrial (1850-1900) interval [4].

The main sectors that are responsible for human emissions of $\mathrm{CO} 2$ are power (energy) supply, transport, industry and buildings, as shown in Fig. 2 [5].

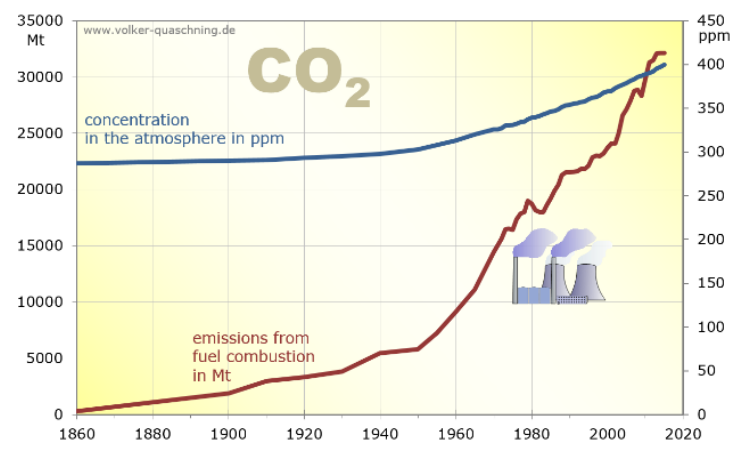

Fig. $1 \mathrm{CO}_{2}$ concentration in the atmosphere (blue line) \& $\mathrm{CO}_{2}$ emissions (red line).

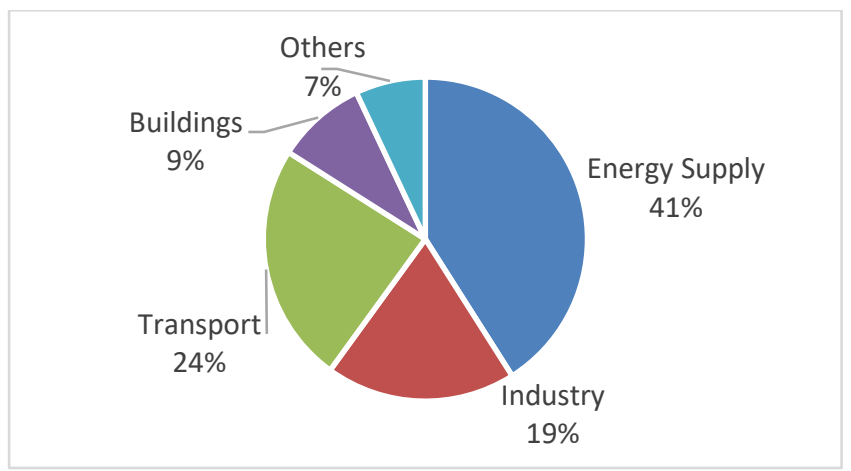

Fig. $2 \mathrm{CO}_{2}$ main emitters by sectors

\section{B. Climate Changes}

Global warming affects the natural balance of the ecosystems, causing climate change manifested in [6]:

- Melting of the fresh water natural reservoirs in the North Pole and ice glaciers. 
- Ocean acidification (by absorbed $\mathrm{CO}_{2}$ ) in addition to temperature rise of the water that cause microorganisms and fish fatalities.

- Sea-level rise (due to expansion of the water by temperature rise) and its drastic effects on coastal cities, people and land. Some effects include saltwater intrusion, groundwater contamination and soil salinization.

- Extreme weather events such as hurricanes, floods, droughts and fires.

- Crop corruption and livestock scarcity

- Humans will suffer from the aggregated effect of above-mentioned consequences of climate change, including poverty, migration, and other social and economic effects.

\section{Paris Agreement (PA)}

In 2015, a historic milestone was achieved during the $21^{\text {st }}$ Conference of Parties (COP21) through the adoption of the Paris Agreement (PA). During PA, 197 parties committed to "Holding the increase in the global average temperature to well below $2^{\circ} \mathrm{C}$ above preindustrial levels and pursuing efforts to limit the temperature increase to $1.5^{\circ} \mathrm{C}$ above preindustrial levels" [7].

\section{Nationally Determined Contributions (NDCs)}

Before PA, each country was required to submit an Intended Nationally Determined Contributions (INDCs), which are transformed to NDCs when each country officially ratify the PA. NDCs allow each country to develop its own climate actions according to its own resources, needs, capacities and priorities. NDCs will come into force in 2020 and updated every five years thereafter [8].

The main component of NDCs is Mitigation. Mitigation involves all actions aimed to reduce the concentration of GHGs in the atmosphere. Another optional component in the NDCs is Adaptation. Adaptation involves all actions (reactions) taken to reduce the negative impacts of climate change [9].

The latest report of the United Nations Framework Convention on Climate Change (UNFCCC), shows that if all governments achieved their committed NDCs, the world will warm $3 \sim 5^{\circ} \mathrm{C}$, far beyond the PA agreement [10].

Technically, it is still possible to bridge the gap, but if NDCs ambitions are not increased before 2030, exceeding the $1.5^{\circ} \mathrm{C}$ goal can no longer be avoided [11].

The special report of the Intergovernmental Panel on Climate Change (IPCC) warned of the major negative impacts of a rise in global temperatures of $2^{\circ} \mathrm{C}$, and the lower consequences of $1.5^{\circ} \mathrm{C}$ global warming [12]. 


\section{2- Egypt's Case Study}

\section{A. Egypt's Emissions}

The exact figure for GHG emissions or $\mathrm{CO}_{2}$ emissions in Egypt may be confusing. The Third National Communication (TNC) of Egypt to the UNFCCC estimated the amount of GHG emissions by $248 \mathrm{MtCO}_{2} \mathrm{eq}$, with $\mathrm{CO}_{2}$ share of $168 \mathrm{MTCO}_{2}(68 \%)$. The TNC was released in 2016 and it included figures from 2005 [13].

Egypt's Sustainable Development Strategy (SDS), published in 2016, showed that the total GHG emissions of 2015 were $276 \mathrm{MtCO}_{2} \mathrm{eq}$ [14].

The Central Agency for Public Mobilization and Statistics (CAPMAS) reported that $\mathrm{CO}_{2}$ emissions in Egypt for the fiscal year 2016/2017 were $210 \mathrm{MtCO}_{2}$. The biggest single source of $\mathrm{CO}_{2}$ emissions is the electricity sector $(43 \%)$. Other major contributors were the transport sector (19\%); the industrial sector (15\%) and the buildings sector (8\%) [15].

Foreign estimates reported that Egypt emits $219 \mathrm{MtCO}_{2}$ in 2017 with a percentage of $0.6 \%$ of global emissions, ranking 27 worldwide [16]. The latest estimate was $250 \mathrm{MtCO}_{2}$ in 2018, and this most recent figure will be the basis of our study [17].

\section{B. Egypt's Vulnerability to Climate Change}

Egypt has communicated three National Communications to the UNFCCC in 1999, 2010 and 2016 respectively. The Second National Communication (SNC) addressed the vulnerability and adaptation of various sectors in Egypt to potential impacts of climatic changes. The Third National Communication (TNC) updated the vulnerability and adaptation assessment with a focus on health, tourism and biodiversity. Egypt is highly vulnerable to climate change and its impacts can be summarized as follows [18]:

- $\quad$ Fresh water deficiency. Combined with increased water demand (drinking water for > 100 Million people, irrigation water for existing 8.5 Million Feddan and 1.5 Million Feddan new land), together with trans-boundary tensions with Ethiopia. In addition, an anticipated decrease in the precipitation of the rainfall by $7 \%$ and likely increase in droughts.

- $\quad$ Sea level rise. Due to its low elevation, the Mediterranean shoreline, including the Nile Delta, is very vulnerable to sea level rise. Projections for 2100 suggests a one-meter sea level rise with a high tide of $30 \mathrm{~m}$, which will significantly change the Nile Delta region.

- Agriculture in the Nile Delta's lands will be significantly affected by saltwater intrusion, groundwater contamination, soil salinization, reduced crop yields, deterioration of crop quality, increased food insecurity, livestock losses and other social and economic impacts.

- $\quad$ Fisheries will be affected by increased temperature, micro-organism fatalities and fish species immigration.

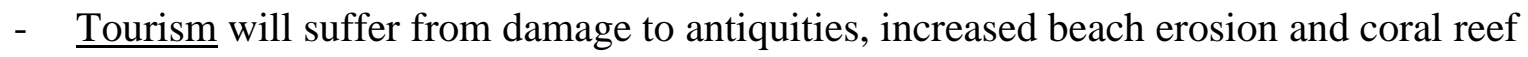
loss.

- Human Health will suffer from increased heat stress, increased rate of respiratory diseases, death and injury due to storms. 


\section{3- Egypt's Nationally Determined Contributions: A Review}

\section{A. Egypt's Intended Nationally Determined Contribution (INDC)}

Egypt submitted its INDC in November 2015. The Egyptian Ministry of Environment officially communicated the NDC to the UNFCCC in June 2017 [19].

In fact, no change was made to the INDC. The official NDC still holds the title "Egyptian Intended Nationally Determined Contribution". The INDC is a 13-page black and white document available only in English language on the UNFCCC NDC Interim Registry site. Egypt's INDC consists of six chapters summarized as follows [20]:

- Chapter 1 gives a general introduction to Egypt's INDCs.

- Chapter 2 reviews Egypt's national circumstances at the year of the report (2015). Items discussed are high population growth (89 million, with a growth rate of $2.2 \%$ annually), unemployment rate (13\%) and foreign debts (47 billion \$). The report refers to Egypt's vision 2030. Some planned national Mega projects are mentioned.

- Chapter 3 presents climate change risks to Egypt along with adaptation and mitigation actions. Risks include reduced crop productivity. Sea level rise and salt-water intrusion to the Nile delta will negatively affect the agricultural land and livestock production. Sea level rise (by $50 \mathrm{~cm}$ ) will lead to high population migration from coastal cities. Historical heritage and coral reefs will be affected by climate changes, which will negatively affect tourism. Other effects on health and energy sectors are also represented. Adaptation actions are presented in general terms without quantification. The same applies for mitigation actions to reduce $\mathrm{CO} 2$ emissions, including promoting energy efficiency, renewables and nuclear power, without quantification.

- Chapter 4 presents the possibility of establishing national market for carbon trading.

- Chapter 5 estimates the cost of implementing adaptation and mitigation measures during the period $2020-2030$ by 73 billion $\$$. No breakdown is given to this figure.

- Chapter 6 calls for external financial support from international funding authorities to implement this INDC.

\section{B. Criticism of Egypt's INDCs}

- The NDC submitted is the same INDC, which is submitted almost two years earlier. Review of some information may be needed due to the rapidly changing economic circumstances.

- No cross reference was made to similar efforts, especially the TNC.

- No indication is made of involvement of any other stakeholders or parties or even authors of the report other than the Egyptian Government.

- There is a clear need for quantification throughout the NDC especially with respect to mitigation actions including quantifying emission reductions and expectations, and details of projected costs.

- The primary focus of the NDC is the adaptation component. This is well understood considering Egypt's exposure to the adverse effects of climate change and its current 
economic situation, which is a limiting factor on its mitigation potentials (Rowihil, 2017).

- The NDC is conditional; the fulfilment of the NDC is dependent on international financing.

- Some typing mistakes should be corrected; for example, in the title page, the word "Contribution" is used instead of "Contributions" and in the 2nd page, the phrase "United Nation" is used instead of "United Nations", . . .

\section{4- Proposed Egypt's NDC}

\section{A. Energy Sector}

The current energy mix for electricity supply in Egypt (during the fiscal year 20172018 ) is $75 \%$ gas, $17 \%$ oil, $7 \%$ hydro \& $1 \%$ renewables. Based on the current energy mix, the amount of emitted $\mathrm{CO}_{2}$ due to power generation is estimated at $\sim 120 \mathrm{MtCO}_{2}$ [21]. In this section, we will discuss three scenarios for supplying future loads by 2030 :

\section{i) Diversified Energy Mix Scenario}

This scenario is proposed in Egypt Vision 2030. Instead of relying on oil and gas (92\%), Egypt aims at a diversified energy mix by 2030 , that can add to the existing $35 \mathrm{GW}$ generating capacities (as of 2016) about $51 \mathrm{GW}$, to reach $86 \mathrm{GW}$ of generating capacities by 2030. The proposed energy mix in this scenario will consist of $29 \%$ coal, $27 \%$ oil and gas, $16 \%$ solar, 14\% wind, 9\% nuclear and 5\% hydro. This scenario, shown in Fig. 3 (A), will introduce coal for the first time in Egypt. It will also makes it the main source. Coal, besides being imported, is the dirtiest source of fossil fuel. This scenario will increase the $\mathrm{CO}_{2}$ emissions from power sector from baseline value of $\sim 120 \mathrm{MtCO}_{2}$ to $\sim 280 \mathrm{MtCO}_{2}$. Experience of environmental protection in Egypt regarding applying environmental regulations is not encouraging the use of coal, under any supposed technology, including Clean Coal Technology (CCT) [22-24].

ii) fossil-based Scenario

During 2016-2018, several natural gas discoveries were announced in Egypt that might shift the country's vision towards a more dependence on the natural gas. Three gas power stations with a total capacity of $14.4 \mathrm{GW}$ were built by Siemens, and put into operation by the end of 2018. Growing interest in renewables worldwide had led to falling prices of oil. These circumstances may shift the government interest to implement a Business as Usual (BaU) scenario that depends on oil \& gas $(60 \%)$, accompanied by a substantial contribution of coal $(22 \%)$, nuclear (6\%) and renewables \& hydro (12\%). Under this scenario, shown in Fig. 3 (B), the $\mathrm{CO}_{2}$ emissions from the electricity sector will reach $\sim 306 \mathrm{MtCO}_{2}$ instead of baseline value of $\sim 120 \mathrm{MtCO}_{2}$. This scenario is worse than the previous one due to large dependence on fossil fuel [24-25].

\section{iii) Low-emission Scenario}

The government announced its plan to achieve $20 \%$ renewables of total generating capacities by 2022 . This share will increase to $37 \%$ in 2030 and to $42 \%$ in 2035 . Although the renewable sources of power generation can be used efficiently at very decentralized and local scales, yet intermittent nature of these technologies does not permit to provide a large-scale continuous 
base-load power. Therefore, a power generation strategy based on $60 \%$ Combined Cycle Gas Turbine (CCGT), 35\% renewables \& hydro and 5\% nuclear may be realistic. This is shown in Fig. 3 (C). The $\mathrm{CO}_{2}$ emission factor for CCGT is less than $400 \mathrm{gm} \mathrm{CO}_{2} / \mathrm{kWh}_{\text {generated energy }}$ compared to $\sim 600 \mathrm{gm} \mathrm{CO} / \mathrm{kWh}$ in case of conventional steam or gas turbine power plants. Hydroelectric power, although taken to the throat, can be amended by pumping and storage technology. Under this scenario, the $\mathrm{CO}_{2}$ emissions from the electricity sector will reach $\sim 75$ $\mathrm{MtCO}_{2}$ instead of baseline value of $\sim 120 \mathrm{MtCO}_{2}$. This NO COAL scenario is the only scenario that can cause the $\mathrm{CO}_{2}$ emissions to decrease with an increase of the generating capacity [2425].

\section{iv) General Recommendations}

In addition to generation decarbonization, other potentials exist in decreasing the losses in the transmission and distribution system from current $15 \%$ to $12 \%$ in 2022 and to $8 \%$ by 2030 . Energy efficiency for end users can lead to lower demand of energy services. Replacing 400W sodium lamps in street lighting with equivalent 150W LED lighting will reduce the $6 \%$ share of public lighting in consumed energy to approximately $2 \%$. More reductions could be achieved for lightning in the residential sector.

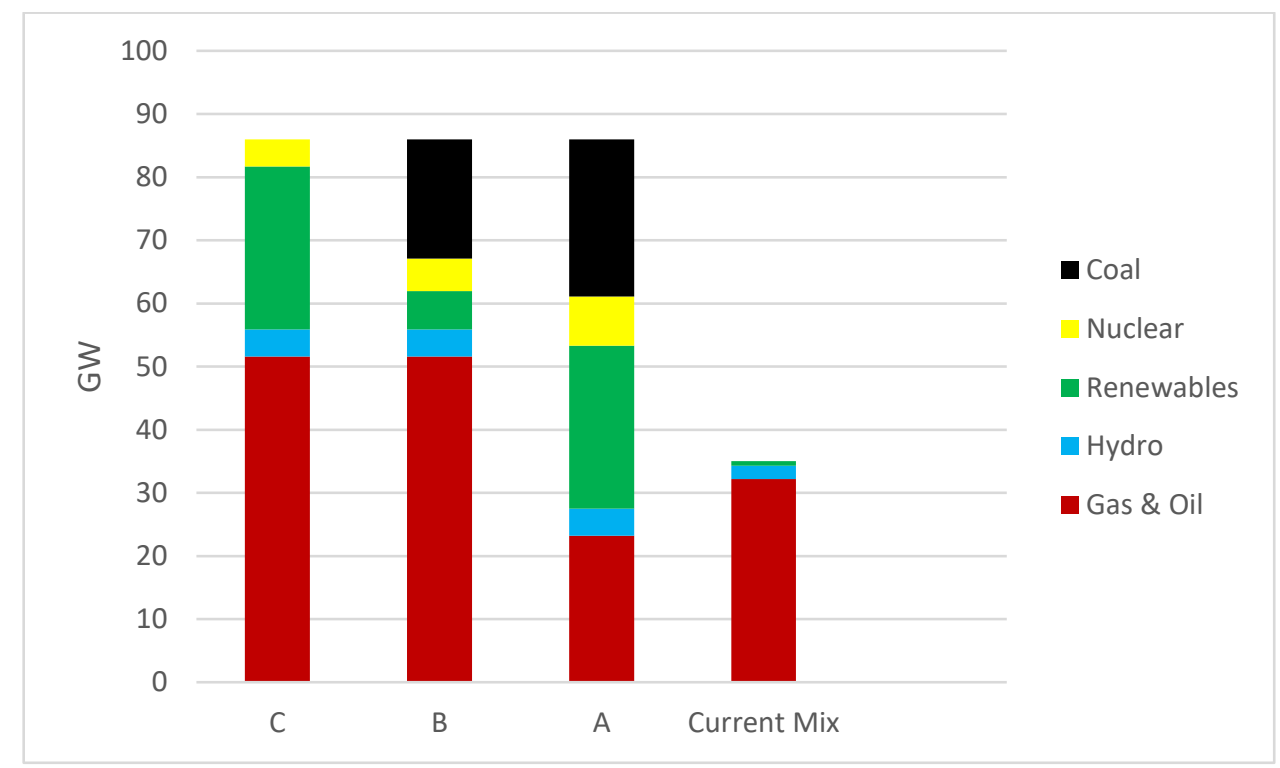

Fig. 3 Current energy mix (2016) versus diversified scenario (A), business as usual scenario (B) and low emission scenario (C)

\section{B. Transport Sector}

The transport sector comes in the second place regarding $\mathrm{CO}_{2}$ emissions in Egypt, with approximately $19 \%$. The transport sector's rising fuel costs and polluting emissions is a priority among planners and policy-makers in Egypt, especially in light of the fiscal burden of fuel subsidies [26].

i) Electric Mobility

With approximately 10 million vehicles in Egypt, Electric Vehicles (EVs) are seen as the most appropriate shift from both market and governance outlook [27]. 
In February 2018, Egypt's first electric vehicle charging station was opened. In November 2018, fifteen electric buses began operation in Alexandria. In April 2019, the Egyptian government signed an agreement with a Chinese automaker for the joint manufacture of 2,000 electric buses within four years.

ii) Fuel Switching

Another driver is fuel switching from gasoline to natural gas, at least as an intermediate stage. In the capital Cairo, 45,000 Taxis were replaced by newer ones. The new Taxis use up-to-date technology that reduces pollution through lower fuel consumption. More than half of the new vehicles run on Compressed Natural Gas (CNG), which is a type of environment-friendly fuel that generates minimal GHG emissions. After the project's success in Cairo, the Government of Egypt is now considering replicating the same model in other governorates.

iii) General Recommendations

Customer-oriented efforts can be very effective in decreasing the total pollution from the transport sector. These efforts include shaping consumer culture towards buying cars that consume less gasoline and promoting public passenger transport, especially inside crowded cities like Cairo and Alexandria. Another opportunity comes from increasing the share of nonroad transport (including Metro). Water transport within the Nile river is overlooked, especially for cargo transport. Some other actions like availing lanes for bicycles along with country-wide campaigns for promoting this emission-free means of transportation, especially within students, can add to the efforts to decrease emissions from the transport sector [28].

\section{Industry Sector}

The industrial sector comes in the third place regarding $\mathrm{CO}_{2}$ emissions in Egypt, with approximately $15 \%$. Considering an aging installed base that is mainly fitted with old motors and mechanical regulation systems, huge energy savings can be achieved in almost every single application. To contribute to significant energy efficiency improvements, we must monitor how energy is used and identify specific areas for development.

\section{i) Motor System Efficiency}

Motor systems consume about two thirds of the electrical energy in industry. Improvements in motor systems are summarized in two pathways:

1) Use of high efficient motors IE2 or premium efficiency motors IE3 in replacement of standard efficiency motors IE1 or low-efficiency motors IE0. The Government needs to mandate industries to comply with Minimum Energy Performance Standards (MEPS). If all electric motors were replaced with IE3 motors, the industrial electricity use would be $16 \%$ lower [29].

2) Application of Variable Speed Drives (VSDs). VSDs match the motor output to the load requirements, especially for varying loads like pumps and fans, instead of operating the motor with full speed (and power) and then throttling or damping the output to get the required flow. According to the application, energy savings can reach 20\% 50\% [30].

ii) Waste Heat Recovery

Industrial waste heat is the energy that is generated in industrial processes which is lost, wasted 
and escaped into the environment. Waste heat recovery methods include capturing and transferring the waste heat from a process back to the system as an extra energy source. The energy source can be used to create additional heat or to generate electrical and mechanical power. Some proven technologies include zero flaring, heat pumps and the use of Organic Rankine Cycle (ORC) to generate power from low-grade heat [31].

\section{Buildings Sector}

\section{i) The existing Buildings}

The existing building stock in Egypt consumes more than $60 \%$ of the electrical energy. Improving the energy performance in buildings can be done by using more efficient energyusing equipment. Replacing incandescent or fluorescent lighting with LED lighting can save approximately $50 \%$ of the lighting loads. Using central and more energy efficient air conditioners can save up to $35 \%$ of HVAC loads. Installing Photo Voltaic (PV) solar panels can reduce the total load according to the area used. Shaping the occupants' behavior concerning energy usage can be most beneficial. A national action plan is required to be implemented immediately in Egypt aiming for energy conservation actions in the existing building sector, which can save energy and decrease the associated $\mathrm{CO}_{2}$ emissions [32].

\section{ii) The future (Smart) Buildings / Cities}

Egypt announced recently the launch of the fourth generation of the Egyptian new cities, based on the smart city approach. It aims to carry out that vision in its new administrative capital, New El-Alamein, and eastern Port Said cities, among others. The better performance as mentioned can come through engaging citizens, government, and each other stakeholders [33]. A smart sustainable city is an innovative city that uses information and communication technologies (ICTs) and other means to improve quality of life, efficiency of urban operation and services, while ensuring that it meets the needs of present and future generations with respect to economic, social, environmental, as well as cultural aspects. In a smart city, energy is generated, stored and used locally as much as possible for maximum efficiency. Citizens increasingly have the opportunity to generate their own energy through a variety of sustainable methods. Additionally, peer-to-peer energy exchange, in which energy that is generated by solar panels on rooftops and that exceeds the demand of the building itself, can safely and efficiently be used by surrounding buildings.

\section{5- RESULTS \& DISCUSSION}

In this paper, Egypt's NDCs submitted to the UN in accordance with Paris Agreement on Climate Change were reviewed. It was shown that the existing NDCs lack the ambition and the quantification required to express Egypt's true potential and intention towards contribution to reduce $\mathrm{CO}_{2}$ emissions. Because of the impact of climate change, Egypt insists that any agreement must take the adaptation as a first priority. Mitigation is in the second priority after adaptation. In this regard, the Egyptian INDC focus on national needs of adaptation.

The paper discussed the four main sources of emissions in Egypt; power (energy) generation, transport, industry and buildings. Energy sector can reduce its current emissions by shifting 
towards a low-emission scenario that depends on $60 \%$ natural gas $+35 \%$ renewables \& hydro $+5 \%$ nuclear. This is a NO COAL scenario. Alone, this scenario can achieve the target of reducing the overall emissions by $20 \%$ by 2030 . Transport sector can benefit from increased penetration of electric vehicles and switching from gasoline to compressed natural gas in traditional cars. Industry sector can benefit from the spread of high efficient motors and variable speed drives, together with waste heat recovery. Buildings sector can benefit from replacing lighting systems with LED, improved air conditioning systems, installing PV solar panels and shaping occupants' behavior. These NDCs should be transferred into action plans on the national level such that they will be applied in a systematic framework that ensures achieving the NDCs' goals. The Egyptian government must prepare and communicate a separate document concerning National Adaptation Plan (NAP) and submit it to the funding mechanisms within the UN, along with the costs of adaptation to climate change, in order to receive the required funding for such adaptation actions.

\section{References}

[1] D. W. Kweku et al., "Greenhouse effect: Greenhouse gases and their impact on global warming”, Journal of Scientific Research \& Reports, Vol. 17(6), pp. 1-9, 2017.

[2] G. D. Myhre et al., “Anthropogenic and natural radiative forcing”. In: climate change 2013: The physical science basis. Contribution of working group I to the fifth assessment report of the Intergovernmental Panel on Climate Change (IPCC), 2014.

[3] V. Smil, "Carbon emissions rising despite European and North American efforts to reduce them", IEEE Spectrum, 2019.

[4] Climate Action Tracker (CAT), "Warming Projections Global Update", 2018.

[5] M. Heinrich and L. Wong, "New energy solutions for $1.5^{\circ} \mathrm{C}$ Pathways and technologies to achieve the Paris Agreement”, World Business Council for Sustainable Development, 2018.

[6] World Meteorological Organization (WMO), "Statement on the State of the Global Climate in 2018", 2019.

[7] United Nations (UN), "Paris Agreement", 2015.

[8] K. Levin et al., "Designing and preparing Intended Nationally Determined Contributions (INDCs)", World Resources Institute (WRI) and United Nations Development Programme (UNDP), 2015.

[9] F. Taibi and S. Konrad, "Pocket guide to Nationally Determined Contributions (NDCs), European Capacity Building Initiative (ECBI), 2018

[10] United Nations Framework Convention on Climate Change (UNFCCC), "UN Climate Change Annual Report: 2018", 2019.

[11] United Nations Environment Programme, "Emissions Gap Report 2018”, 2018.

[12] IPCC, “Global Warming of $1.5^{\circ} \mathrm{C}$ ", IPCC Special Report (SR15), 2018.

[13] Egyptian Environmental Affairs Agency (EEAA), "Egypt Third National Communication under the United Nations Framework Convention on Climate Change", 2016.

[14] Ministry of International Cooperation, Arab Republic of Egypt, "Sustainable Development Strategy (SDS): Egypt Vision 2030", National Voluntary Review, 2016.

[15] Egypt Today, "Egypt's CO2 emissions up by 1.8 percent: CAPMAS”, 2018.

[16] Ministry of Foreign Affairs of the Netherlands, "Egypt: Climate Change Profile", 2018.

[17] M. Crippa et al., "Fossil CO2 and GHG emissions of all world countries - 2019 Report", Joint Research Centre (JRC), Publications Office of the European Union, Luxemburg, 2019.

[18] US-AID, "Climate Risk in Egypt: Country Risk Profile", 2018.

[19] Arab Republic of Egypt, "Intended Nationally Determined Contributions", 2015.

[20] M. Rowihil, "A review of Egypt's first NDC", World Maritime University Dissertations, 2017.

[21] Egyptian Electricity Holding Company (EEHC), “Annual Report, 2017-2018”, 2019.

[22] I. Bottoms et al., " 80 Gigawatts of Change: Egypt's Future Electricity Pathways", The Egyptian Center for Economic and Social Rights \& the Heinrich Böll Foundation, 2016. 
[23] L. Abdallah, "Environmental considerations for using coal in Egypt", 25th International Conference: "Environmental Protection is a Must", Alexandria, Egypt, 16 - 18 May 2015.

[24] L. Abdallaha and T. El-Shennawy, "Evaluation of CO2 emissions from electricity generation in Egypt", 1st International Conference on Chemical, Energy and Environmental Engineering (ICCEEE), Alexandria, Egypt, 19-21 Mar., 2017.

[25] M. A. H. Mondal et al., "Long-term optimization of Egypt's power sector: Policy implications", Energy, Vol. 166, pp. 1063-1073, 2019.

[26] H. Korkor, "Policy reforms to promote energy efficiency in the transport sector", 2018.

[27] A. El-Dorghamy, "Mainstreaming electric mobility in Egypt: Policy brief", Center for Environment and Development for the Arab Region and Europe (CEDARE), 2018.

[28]E. Ahmed, "Egypt's policies for sustainable transport", Multi-year Expert Meeting on Transport, Trade Logistics and Trade Facilitation, Geneva, Switzerland, 14-16 Oct. 2015.

[29] International Energy Agency (IEA), “Energy Efficiency 2018, Analysis and outlooks to 2040”, 2018.

[30]L. Abdallaha and T. El-Shennawy, "Environmental and Financial Evaluation of Opportunities for Electrical Energy Conservation in a Petroleum Refinery", 2nd International Conference on New Trends for Sustainable Energy (ICNTSE'18), Alexandria, Egypt, 5-6 Nov. 2018.

[31] H. Jouhara et al., "Waste heat recovery technologies and applications", Thermal Science and Engineering Progress, Vol. 6, pp. 268-289, 2018.

[32] L. Abdallah and T. El Shennawy, "Improving energy performance of existing office buildings", International Journal of Energy Science and Engineering, Vol. 3(3), pp. 29-36, 2017.

[33] U. Konbr, "Smart sustainable cities - vision and reality the Egyptian context as a case study", International Journal on: Proceedings of Science and Technology, pp. 1-20, 2018. 